Ensino, Saúde e Ambiente - V10 (3), pp. $48.72, \mathcal{D e} z .2017$

\title{
DISCURSOS SOBRE JUSTIÇA AMBIENTAL: FORTALECENDO SENTIDOS EMANCIPATÓRIOS NAS PRÁTICAS DA EDUCAÇÃO EM CIÊNCIAS
}

\section{ENVIRONMENTAL JUSTICE DISCOURSES: STRENGTHENING EMANCIPATORY MEANINGS IN THE PRACTICES OF SCIENCE EDUCATION}

\author{
Gabriela Ventura ${ }^{1}$, Laísa Freire ${ }^{2}$ \\ ${ }^{1}$ Instituto Federal de Educação, Ciência e Tecnologia do Rio de Janeiro/Campus \\ Mesquita/gabriela.silva@ifrj.edu.br \\ ${ }^{2}$ Universidade Federal do Rio de Janeiro/ Instituto de Biologia/ Departamento de Ecologia/ Programa de \\ Pós-graduação em Educação em Ciências e Saúde /laisa@ biologia.ufri.br
}

\section{RESUMO}

Neste trabalho, apresentamos uma análise discursiva da Carta Política do VI Encontro Nacional da Rede Brasileira de Justiça Ambiental. Nosso objetivo foi identificar alguns sentidos produzidos por essa rede os quais evidenciam a distribuição desigual dos danos e prejuízos sociais e ambientais, no âmbito do atual modelo hegemônico de desenvolvimento social e político-econômico, conformando as injustiças ambientais. Partimos do pressuposto de que no campo da Educação em Ciências circulam discursos que podem dissimular essas injustiças, reproduzindo relações de dominação e exploração. Sob o aporte teórico-metodológico da Análise Crítica do Discurso, analisamos o texto a partir do significado representacional do discurso, conforme as seguintes categorias analíticas: vocabulário (lexicalização, significados da palavra e metáforas) e intertextualidade (pressuposição e negação). Identificamos alguns sentidos produzidos nesse documento os quais desvelam discursos que limitam a capacidade de superação da crise socioambiental e que mantêm as relações de dominação e exploração que conformam essa crise. Por meio da negação, por exemplo, foram evidenciadas as contradições dos discursos do senso comum, e através de metáforas, foram reforçadas características do atual modelo de desenvolvimento as quais corroboram para as injustiças ambientais. A partir das análises, assinalamos dois sentidos contrahegemônicos que podem ser fortalecidos no campo da Educação em Ciências: os discursos sobre as relações entre seres humanos e natureza e os discursos sobre o atual modelo de desenvolvimento social e político-econômico. Ao caracterizar esses discursos, temos como objetivo colaborar para a construção e o fortalecimento de sentidos emancipatórios nas práticas de Educação em Ciências.

Palavras-chave: Educação em Ciências, Justiça Ambiental, Análise Crítica do Discurso.

\begin{abstract}
In this study we present a discursive analysis of the Political Document of the VI National Meeting of the Brazilian Network of Environmental Justice. Our main goal was to identify some of the meanings produced by this network, which showed the unequal distribution of social and environmental damages and losses within the current hegemonic model of social and political-economic development, that ensures environmental injustices. As a starting point we took into account the assumption that in
\end{abstract}


the field of Education in Sciences there are discourses that can disguise these injustices, reproducing relations of domination and exploration. According to the analytical framework of the Critical Discourse Analysis, we analyzed the text from the representational meaning of discourse, according to the following analytical categories: vocabulary (lexicalization, word meanings and metaphors) and intertextuality (presupposition and negation). We identified some of the meanings produced by this document which reveal discourses that limit the ability to overcome the social and environmental crisis and maintain the relations of domination and exploitation. Through denial, for example, the contradictions of common sense discourses were evidenced and through metaphors, characteristics of the current development model corroborating environmental injustices were reinforced. From the analysis, we pointed out two counter-hegemonic meanings that can be strengthened in the field of Science Education: the discourses about the relations between human beings and nature and the discourses on the current model of social and political-economic development. While characterizing these discourses we aim to collaborate for the creation and strengthening emancipatory meanings in the practices of Science Education.

Key words: Science Education, Environmental Justice, Critical Discourse Analysis.

\section{INTRODUÇÃO}

As sociedades contemporâneas têm vivenciado o agravamento da desigualdade social e da degradação ambiental, conformando uma crise que, em sua gênese, articula inexoravelmente as dimensões sociais, ambientais, políticas e econômicas. Tal crise decorre do atual modelo de desenvolvimento social e político-econômico que concentra riqueza e poder nas mãos de poucos, ao mesmo tempo em que submete diversos grupos sociais e comunidades à exploração, à miséria, à degradação ambiental e social.

O modelo hegemônico de desenvolvimento político-econômico capitalista globalizado e neoliberal é marcado por políticas de liberalização econômica e desregulamentação das trocas do trabalho e das finanças, havendo a concentração do poder de controle da economia mundial nas mãos de um grupo cada vez mais reduzido (VASCONCELOS et al., 2010). No âmbito das mudanças político-econômicas, Chouliaraki e Fairclough (2007) ressaltam a disseminação e a aplicação prática das políticas econômicas do neoliberalismo de forma globalizada. Esses autores corroboram o neoliberalismo como um projeto político-econômico para facilitar a reestruturação das relações sociais atendendo a acelerada expansão do capitalismo globalizado. As políticas neoliberais, de acordo com Trein (2007, p. 116), “aprofundam o processo de alienação nas relações sociais do trabalho que regulam o intercâmbio entre os seres 
humanos e natureza" e Bencze (2007) observa que a globalização econômica subordina as relações sociais à lógica da economia, corroborando injustiças sociais e a degradação ambiental.

A análise desses processos sociais e econômicos, necessariamente, implica compreender que eles determinam as divisões sociais e as relações de exploração (LAYARGUES, 2002). Nos embates hegemônicos pela disputa do projeto societário, convém aos grupos dominantes desenvolver estratégias que permitam dissimular ou ocultar as desigualdades, conflitos e injustiças decorrentes do modelo societário hegemônico. Nesse sentido, Fairclough (2000; 2005) assinala que a inexorabilidade do capitalismo globalizado neoliberal se constitui em uma importante estratégia discursiva para manter o status quo. O discurso neoliberal representa a globalização e as transformações sociais e político-econômicas na economia global como fatos inevitáveis, aos quais todos devem ajustar-se: a população, os Estados nacionais e outros atores sociais, sem vislumbrar possibilidades de transformação social. Esse discurso de inexorabilidade limita as condições de superação da crise socioambiental e a Análise Crítica do Discurso (ACD) colabora para desvelar discursos que limitam a capacidade de transformação dessa crise (VENTURA e FREIRE, 2015).

Os discursos circulam entre as diferentes redes de práticas sociais (reestruturação) e entre as diferentes escalas da vida social (reescalonamento) e podem ser estabelecidos, reproduzidos ou transformados nas práticas sociais, por meio da ação e interação social. Daí decorre a dialética entre discurso e sociedade, entendendo que ao mesmo tempo em que as práticas sociais são constrangidas pelas estruturas sociais, elas também se constituem como espaços de agência social para transformar essas mesmas estruturas, por meio de eventos concretos. A possibilidade de agência humana, portanto, permite que a hegemonia seja compreendida como permanência relativa de articulações de elementos sociais, sempre sob o risco de desarticulação e rearticulação desses elementos (RESENDE e RAMALHO, 2004).

A identificação de mecanismos discursivos que dissimulam as relações de exploração e dominação é fundamental para criar práticas comprometidas com a transformação social, pois "o enfrentamento deste modelo requer que se desfaça a obscuridade e o silêncio que são lançados sobre a distribuição desigual dos riscos ambientais" (BRASIL, 2017). Posto isso, entendemos que circulam pelas redes de 
práticas sociais contemporâneas discursos os quais colaboram para a reprodução do atual modelo hegemônico do capitalismo neoliberal e a sustentação das injustiças e desigualdades conformadas por esse modelo. Esses sentidos são recontextualizados, reproduzidos ou transformados nas ações e interações sociais.

Temos voltado nossos interesses de pesquisa para refletir sobre a construção, a reprodução e transformação de determinados sentidos, nos campos da Educação em Ciências e da Educação Ambiental os quais podem conformar práticas que colaborem para a manutenção ou a transformação do atual modelo de desenvolvimento e suas consequências para as relações sociais e ambientais. A partir do comprometimento do processo de produção científica e tecnológica com esse modelo hegemônico de desenvolvimento social e político-econômico, concordamos com Ventura e Freire (2017) que a Educação em Ciências pode colaborar para reflexões críticas sobre as transformações sociais e político-econômicas contemporâneas e as relações de desigualdade e injustiças decorrentes dessas mudanças. Nesse sentido, o presente texto se insere no contexto de desenvolvimento de uma pesquisa de doutorado que teve como objetivo investigar os discursos na rede de práticas da Educação em Ciências os quais podem contribuir para a dissimulação dos problemas socioambientais e a naturalização das injustiças ambientais nas sociedades contemporâneas.

Podemos afirmar que, cada vez mais, a questão ambiental tem se constituído como parte da agenda de pesquisas no campo da Educação em Ciências (COSENZA et al., 2014) e tem estabelecido diversas possibilidades de interseção entre os campos da Educação Ambiental e da Educação em Ciências (MARTINS et al., 2008; SAUVÉ, 2010; VASCONCELOS et al. 2010; WALS et al., 2014). Além disso, há ainda as aproximações que têm sido estabelecidas entre os referenciais da Educação Ambiental e da Educação em Ciências com a Justiça Ambiental (COSENZA et al., 2014; LOUREIRO e LAYRARGUES, 2013; SANTOS et al., 2015; VASCONCELOS et al., 2014).

Em nosso entendimento, no campo da Educação em Ciências, circulam discursos sobre as relações entre os seres humanos e o ambiente, sobre o atual modelo de desenvolvimento social e político-econômico e sobre o processo de desenvolvimento científico e tecnológico nas sociedades contemporâneas. Esses discursos podem encobrir relações de desigualdade e injustiças sociais e ambientais, por exemplo, o 
discurso do desenvolvimentismo que dissimula as injustiças ambientais nas quais comunidades são colocadas em situação de vulnerabilidade social e ambiental para o estabelecimento de determinado empreendimento econômico. O movimento por Justiça Ambiental, por sua vez, desvela discursos que encobrem as injustiças ambientais, explicitando os mecanismos pelos quais o atual modelo de organização societária estabelece e sustenta relações de dominação. Dessa forma, entendemos que ao caracterizar os discursos ambientais presentes na rede de práticas que compõem o movimento brasileiro por Justiça Ambiental, podemos colaborar para a construção e o fortalecimento de sentidos emancipatórios nas práticas de Educação em Ciências.

No presente trabalho, temos como objetivo explicitar os antagonismos e contradições do sistema capitalista a partir da análise discursiva da Carta Política do VI Encontro Nacional da Rede Brasileira de Justiça Ambiental ${ }^{1}$, enquanto um evento social concreto da rede de práticas que compõem o movimento brasileiro por justiça ambiental. Sob o aporte teórico-metodológico da ACD, identificamos alguns sentidos produzidos nesse documento os quais desvelam discursos que limitam a capacidade de superação da crise socioambiental e que servem de suporte para as relações de dominação e exploração que conformam essa crise. Dessa forma, buscamos responder a seguinte questão: quais são os discursos que dissimulam as injustiças ambientais e a crise socioambiental e que são desvelados pelo Movimento Brasileiro por Justiça Ambiental no texto da Carta Política?

$\mathrm{Na}$ próxima seção, apresentaremos os aspectos teórico-metodológicos que estruturam a análise discursiva realizada e o problema sociodiscursivo que motiva a presente discussão. Em seguida, contextualizaremos a produção do texto da Carta Política, situando-a no âmbito da Rede Brasileira de Justiça Ambiental e, na seção seguinte, apresentaremos a análise discursiva do texto. Por fim, apresentaremos reflexões sobre como os discursos identificados nos textos podem colaborar para o fortalecimento de recursos materiais e simbólicos na rede de práticas da Educação em Ciências, visando possibilidades de transformação social.

\footnotetext{
${ }^{1}$ https://redejusticaambiental.wordpress.com/2014/09/05/carta-politica-do-vi-encontro-nacional-da-redebrasileira-de-justica-ambiental/ 


\section{ASPECTOS TEÓRICO-METODOLÓGICOS DA ANÁLISE CRÍTICA DO DISCURSO}

Este trabalho se apoia nos estudos críticos do discurso, especificamente, na perspectiva teórico-metodológica da Análise Crítica do Discurso (ACD). Chouliaraki e Fairclough (2007) apresentam uma abordagem transdisciplinar da ACD, ressaltando o aprofundamento das bases sociais dessa disciplina. Resende e Ramalho (2004) destacam o compromisso dessa perspectiva com possibilidades de práticas emancipatórias na vida social e, conforme Chiapello e Fairclough (2002), o seu objetivo é refletir sobre as transformações sociais contemporâneas, entendendo o papel do discurso nesses processos.

A partir da centralidade do conceito de prática social, a ACD centra-se na relação dialética entre discurso e sociedade, entendendo o discurso como um elemento constitutivo da prática social. Nesse sentido, discurso é compreendido como elemento semiótico das práticas sociais, e inclui a linguagem e outras formas semióticas (linguagem verbal, linguagem corporal, imagens). Contudo, além do discurso, as práticas sociais são constituídas por outros elementos sociais em relações dialéticas: relações sociais; atividade material (atividade produtiva e os meios de produção); as pessoas com seus valores, crenças, histórias e desejos; ação e interação. Uma prática social articula modos específicos de usar a linguagem, em diferentes modos de ação e interação, envolvendo relações sociais e as pessoas com suas crenças, valores e modos específicos de organização do espaço físico (CHOULIARAKI e FAIRCLOUGH, 2007; FAIRCLOUGH, 2003).

Práticas sociais correspondem ao modo como as pessoas agem na produção da vida social. Por meio da ação social e interação nas práticas sociais, há, consequentemente, a reprodução ou a transformação da estrutura social. As práticas sociais realizam a mediação entre as estruturas sociais (e suas potencialidades linguísticas) e os eventos sociais concretos (as pessoas em suas ações e interações). Assim, ao mesmo tempo em que são constrangidas pelas estruturas sociais, as práticas sociais também se constituem como processos ativos de transformação dessas estruturas, por meio da ação e interação social (CHOULIARAKI e FAIRCLOUGH, 2007). 
O discurso, como um momento da prática social, está presente na ação, na representação da ação, assim como é parte do desempenho da pessoa consoante a sua posição dentro da prática social. Conforme Fairclough (2016):

Quando as pessoas agem, representam, identificam em (textos como parte de) eventos, elas orientam mais ou menos estabelecendo e estabilizando modos de agir, representando e identificando, que são partes de práticas sociais, constituída ao nível das práticas sociais e, portanto, de ordens de discurso (...) (FAIRCLOUGH, 2016, p. 21).

As ordens do discurso constituem o momento discursivo (semiótico) das práticas sociais e correspondem ao modo como agimos (significado acional), ao modo como representamos (significado representacional) e como nos identificamos e identificamos os outros (significado identificacional). Fairclough (2003) relaciona esses modos de significado do discurso aos conceitos de gêneros, representações e estilos, respectivamente. As características semióticas dos textos analisados são selecionadas a partir da diversidade discursiva disponível na rede de práticas sociais (nas ordens do discurso) conforme as possibilidades linguísticas das estruturas sociais.

Os textos, enquanto parte de eventos sociais concretos, podem ser analisados com relação às materializações dos significados acional, representacional e identificacional nas propriedades do texto. Dessa forma, é possível estabelecer relações entre o nível mais concreto do evento social e o nível mais abstrato das práticas sociais, observando quais (e de que modo) gêneros, discursos e estilos são articulados no texto, considerando que alguns são dominantes, enquanto outros são alternativos ou de resistência (FAIRCLOUGH, 2003).

No presente texto, analisamos o texto da Carta Política enquanto parte de um evento social concreto da rede de práticas sociais, que compõem o movimento brasileiro por justiça ambiental. Analisamos o texto a partir do significado representacional, conforme as seguintes categorias analíticas: vocabulário (lexicalização, significados da palavra e metáforas) e intertextualidade (pressuposição e negação). Por meio da interdiscursividade, identificamos diferentes discursos que são articulados no texto e o modo como eles são articulados. Resende e Ramalho (2006, p. 72) assinalam que "as maneiras particulares de representação de aspectos do mundo podem ser especificadas por meio de traços linguísticos, que podem ser vistos como "realizando" um discurso", e um desses traços principais é o vocabulário. Assim, voltamo-nos para analisar os 
processos de lexicalização e os sentidos das palavras, considerando que "as estruturações particulares das relações entre as palavras e das relações entre os sentidos de uma palavra são formas de hegemonia”. Analisamos, também, as metáforas, considerando suas implicações políticas e ideológicas.

Estudamos os sentidos ideológicos evidenciados pela Carta Política, entendendo ideologia como os sentidos que servem para manter, reproduzir ou transformar relações assimétricas de poder (FAIRCLOUGH, 2003). De acordo com Thompson (2011), relações de dominação são relações sistematicamente assimétricas de poder; essas relações não se restringem às relações de classe e incluem relações de poder, por exemplo, entre gêneros, entre raças e entre países. Nessa perspectiva, entendemos as injustiças ambientais como relações de dominação que se conformam com a crise socioambiental.

\section{A EDUCAÇÃO EM CIENCIAS E OS PROBLEMAS SOCIOAMBIENTAIS: REPRODUÇÃO OU TRANSFORMAÇÃO SOCIAL?}

No âmbito do neoliberalismo como modelo político-econômico hegemônico de desenvolvimento, os processos de produção da vida na sociedade capitalista caracterizam-se pelo aumento da perda dos direitos sociais dos trabalhadores e uma menor capacidade de regulação, pelo Estado, da relação entre capital e trabalho, além dos problemas ambientais (TREIN, 2007).

No âmbito acadêmico, há algumas perspectivas que estabelecem relações entre o neoliberalismo, a globalização econômica e a Educação em Ciências. Bencze et al (2014), por exemplo, assinalam que a Educação em Ciências pode colaborar para que os estudantes possam refletir sobre as diversas implicações dos problemas, das vantagens e das mudanças relacionadas com o atual cenário de globalização econômica. Concordamos também que os educadores precisam refletir sobre as implicações da globalização econômica e da agenda neoliberal, tendo em vista as inúmeras transformações sociopolíticas, econômicas, culturais e ambientais nas sociedades contemporâneas (BAZZUL, 2012; BENCZE e CARTER, 2011). De acordo com Bencze et al (2014), enquanto a Educação em Ciências está voltada para a transmissão de conceitos e fenômenos científicos, suas áreas de formação e atuação podem estar 
colaborando com práticas reprodutoras do atual modelo societário. Martins et al. (2008) observam nas práticas da Educação em Ciências:

(...) as abordagens que vão além da discussão acerca do que o cidadão precisa saber sobre ciência o fazem dentro de uma perspectiva funcionalista, na qual o indivíduo formado seria capaz de contribuir para o progresso da sociedade e não de questionar suas bases, problematizar suas contradições, refletir sobre seu papel social e vislumbrar possibilidades de transformá-la (MARTINS et al., 2008, p. 136).

Posto isso, partimos do pressuposto de que há discursos no campo da Educação em Ciências que podem colaborar para a manutenção e reprodução de problemas socioambientais. Consideramos, ademais, que, nessa rede de práticas sociais, residem, todavia, possibilidades de transformação social pela agência humana, pois conforme Fairclough (2001, p. 33), "o uso da linguagem é, entretanto, constitutivo tanto de formas socialmente reprodutivas quanto de formas criativas, socialmente transformativas (...)”.

Sob esse viés compreensivo, Ventura e Freire (2017) analisam os discursos sobre as finalidades da Educação em Ciências, buscando compreender em que medida esse campo pode colaborar para a manutenção ou para superação da crise socioambiental e as relações de dominação dela decorrentes e apontam dois discursos importantes que representam os objetivos do ensino de Ciências Naturais: reconstruir as relações entre seres humanos e natureza e, compreender o processo de desenvolvimento científico e tecnológico. Tais objetivos possibilitam:

(...) que a Educação em Ciências possa discutir os valores e procedimentos que orientam as relações sociais e ambientais, no atual sistema societário, marcadas pela desigualdade social, pelos vínculos precários de emprego, pela exploração nas relações de trabalho e expropriação de diversos grupos sociais (VENTURA e FREIRE, 2017, p. 320).

Essas questões assumem relevo a partir do conceito de Justiça Ambiental que segundo Acselrad (2010), pode ressignificar a questão ambiental. Esse conceito evidencia os antagonismos e as contradições das relações entre os seres humanos e o ambiente, no âmbito do atual modelo hegemônico de desenvolvimento social e políticoeconômico, por isso colaborando para fortalecer a crítica a esse modelo e suas consequências para as injustiças ambientais.

Face ao exposto, realizamos a presente análise entendendo que os discursos produzidos pela Rede Brasileira de Justiça Ambiental representam essas questões sob uma perspectiva contra-hegemônica, explicitando contradições desse modelo e 
evidenciando mecanismos de dissimulação da crise socioambiental e naturalização das injustiças ambientais.

\section{O MOVIMENTO BRASILEIRO POR JUSTIÇA AMBIENTAL}

O termo Justiça Ambiental surgiu ao final da década de 1970 nos EUA, a partir da constatação de que a disposição de aterros de rejeitos tóxicos concentrava-se em bairros habitados por negros (MARTINEZ-ALIER et al., 2014; PACHECO, 2008), evidenciando a distribuição desigual dos riscos e danos ambientais ou, conforme Acselrad (2010, p. 111), a "lógica socioterritorial que torna desiguais as condições sociais de exercício dos direitos". Dessa forma, deu-se visibilidade à relação entre justiça social e degradação ambiental, mediante degradação ambiental e social para uns e riquezas e lucros crescentes para outros (PACHECO, 2008).

$\mathrm{O}$ conceito de Justiça Ambiental evidencia que os riscos e danos ambientais decorrentes do desenvolvimento econômico são distribuídos de forma desigual, sendo impostos aos grupos sociais historicamente discriminados e marginalizados, em situação de vulnerabilidade social e ambiental, agravando ainda mais a sua opressão social.

No Brasil, com a Conferência da ONU realizada no Rio de Janeiro em 1992, as discussões sobre as questões de justiça ambiental culminaram na constituição do Fórum Brasileiro de ONG e Movimentos Sociais para o Meio Ambiente e o Desenvolvimento. Esse fórum buscava articular a temática ambiental às discussões sobre as buscas de modelos de organização societário alternativos ao modelo dominante de desenvolvimento (ACSELRAD, 2010).

Em 1998, representantes do Movimento de Justiça Ambiental dos Estados Unidos estiveram no Brasil de modo a buscar estratégias de resistência aos casos de injustiça ambiental e articularam contatos com ONG e grupos acadêmicos. Em 2001, estimulado pelo debate que se iniciara em 1998, foi realizado o I Colóquio Internacional de Justiça Ambiental e Cidadania, na cidade de Niterói, no Rio de Janeiro, tendo como tema central a injustiça ambiental que caracteriza o modelo de desenvolvimento dominante no Brasil (ACSELRAD, 2010). Nessa ocasião, foi criada a Rede Brasileira 
de Justiça Ambiental ${ }^{2}$ (RBJA), como resultado da iniciativa de movimentos sociais, sindicatos de trabalhadores/as, ONGs, entidades ambientalistas, ecologistas, organizações de afrodescendentes e indígenas e pesquisadores/as universitários/as. Essa rede se consolidou em 2002 e se constitui “como um espaço de identificação, solidarização e fortalecimento dos princípios de Justiça Ambiental - marco conceitual que aproxima as lutas populares pelos direitos sociais e humanos, a qualidade coletiva de vida e a sustentabilidade ambiental" (RBJA).

O Manifesto de Lançamento da $\mathrm{RBJA}^{3}$, assinado por todas as entidades que formam a rede, encontra-se disponível no site do Ministério do Meio Ambiente e ressalta a motivação da criação da rede:

Pensamos que o tema da justiça ambiental - que indica a necessidade de trabalhar a questão do ambiente não apenas em termos de preservação, mas também de distribuição e justiça - representa o marco conceitual necessário para aproximar em uma mesma dinâmica as lutas populares pelos direitos sociais e humanos e pela qualidade coletiva de vida e a sustentabilidade ambiental. Por esse motivo criamos a Rede Brasileira de Justiça Ambiental (...) (BRASIL, 2017).

A FIOCRUZ, em parceria com a FASE (Federação de órgãos para Assistência Social e Educacional) e com o apoio do Departamento de Saúde Ambiental e Saúde do Trabalhador do Ministério da Saúde, elaborou um mapeamento dos diversos casos de injustiça ambiental discutidos em fóruns e redes com o objetivo de compartilhar informações e potencializar ações de resistências de populações e grupos sociais afetados ou ameaçados pelo modelo atual de desenvolvimento. Esse mapeamento denominado "Mapa de conflitos envolvendo injustiça ambiental e saúde no Brasil"4 reúne casos denunciados desde janeiro de 2006 e as fontes de informação provêm, em grande parte, do acúmulo da Rede Brasileira de Justiça Ambiental (RBJA), incluindo a experiência de suas entidades, suas discussões e seus Grupos de Trabalho.

O movimento por Justiça Ambiental explicita as contradições do atual modelo hegemônico de desenvolvimento social e econômico, situando-se na contra-hegemonia:

(...) o movimento por justiça ambiental se caracteriza em oposição à corrente conservadora do pensamento ambientalista da 'modernização ecológica', atualmente hegemônica e que concebe: a) a natureza como composta apenas por recursos naturais (destituída de componentes socioculturais); b) a existência de problemas ambientais (e não de conflitos socioambientais); c) o

\footnotetext{
${ }^{2}$ https://redejusticaambiental.wordpress.com/

${ }^{3} \mathrm{http} / / / \mathrm{www} . \mathrm{mma}$.gov.br/destaques/item/8077

${ }^{4}$ http://www.conflitoambiental.icict.fiocruz.br/ 
enfrentamento de tais 'problemas' por meio de medidas administrativas e tecnológicas (e não por meio de processos políticos), uma vez que se considera tratar de desperdício ou escassez de recursos ambientais (e não do acesso e uso desigual dos bens ambientais) (LOUREIRO e LAYRARGUES, 2013, p. 64).

Mediante o exposto, a seguir apresentaremos os sentidos produzidos pela Rede Brasileira de Justiça Ambiental, entendendo-os como discursos que evidenciam as relações de dominação e as contradições do sistema capitalista que conformam a crise socioambiental. Com isso, pretendemos refletir sobre possibilidades discursivas que possam colaborar para a construção e fortalecimento de discursos contra-hegemônicos no campo da Educação em Ciências e, assim, contribuir para a formação de estudantes que sejam capazes de criar práticas comprometidas com transformação social.

\section{ANÁLISE DISCURSIVA: A CARTA POLÍTICA DO VI ENCONTRO NACIONAL DA REDE BRASILEIRA DE JUSTIÇA AMBIENTAL}

O I Encontro da Rede Brasileira de Justiça Ambiental ocorreu em 2004, na cidade do Rio de Janeiro, reunindo representantes de uma grande diversidade de movimentos sociais e populares, pesquisadores e ONGs que atuam nas várias regiões do país: representantes de populações tradicionais e extrativistas, de comunidades afetadas por grandes projetos de infraestrutura, de comunidades e trabalhadores que sofrem os impactos do modelo agrícola baseado na grande propriedade e na mecanização e de populações afetadas pela contaminação industrial e urbana.

Em 2014 foi realizada a sexta edição desse evento, entre os dias 22 e 24 de julho, na cidade de Belo Horizonte, em Minas Gerais. O VI Encontro Nacional da RBJA teve como tema: "Reafirmando lutas e estratégias coletivas por Justiça ambiental" e teve como objetivo:

(...) desenvolver estratégias que propiciem a circulação de informações, a troca de experiências e contribuam para fortalecer sujeitos coletivos e coalizões capazes de se contrapor ao processo de concentração de poder na apropriação dos bens ambientais e de fortalecer os sujeitos políticos que enfrentam diretamente as consequências das políticas de desenvolvimento em curso $^{5}$.

\footnotetext{
${ }^{5}$ Disponível em: http://www.pacs.org.br/2014/07/22/vi-encontro-nacional-da-rede-brasileira-de-justicaambiental-reafirmando-lutas-e-estrategias-coletivas-por-justica-ambiental/ 
Ao final do evento, foi elaborada a Carta Política do VI Encontro Nacional da Rede Brasileira de Justiça Ambiental. O texto tem cinco laudas e é assinado pela Rede Brasileira de Justiça Ambiental. A autoria do texto é explicitada no primeiro parágrafo do texto que se inicia pelo pronome "nós" de modo a significar um coletivo que tem objetivos em comum: "comprometidos com a luta por Justiça Ambiental". Todo o texto é redigido na $1^{\mathrm{a}}$ pessoa do plural, demarcando a construção de uma identidade coletiva para os diferentes grupos que compõem a rede e assinam o documento. Essa coletividade, no entanto, não é representada de forma genérica; antes são explicitados os diferentes grupos sociais que participaram do encontro e que são os autores do texto:

(...) somos integrantes de movimentos sociais do campo, das florestas e da cidade, de povos e comunidades tradicionais, de organizações nãogovernamentais e pesquisadores, moradores e moradoras de zonas de sacrifício ou ameaçadas pelo atual modelo de desenvolvimento (RBJA, 2014, p. 1).

Esse trecho já localiza a crítica ao atual modelo de desenvolvimento e evidencia a assimetria de poder entre esse modelo e os grupos que compõem o movimento, conforme a oração "ameaçadas pelo atual modelo de desenvolvimento".

Os autores do texto identificam os diversos grupos sociais que integram o movimento ao adotar a linguagem não sexista, sendo o plural do gênero masculino, derivando do gênero feminino - isso demarca o sentido contra-hegemônico do uso da linguagem sexista que considera o plural no gênero masculino. Assim, evidenciam a crítica as relações assimétricas de poder entre os gêneros masculino e feminino.

(...) agricultoras (es), brejeiras (os), catadoras (es) de caranguejos, geraizeiras (os), quilombolas, marisqueiras (os), pescadoras (es), povos indígenas, povos de terreiro, ribeirinhas (os), vazanteiras (os), militantes de organizações da sociedade civil, religiosas (os), estudantes, pesquisadoras (es), professoras (es) comprometidos com a luta por Justiça Ambiental (RBJA, 2014, p.1).

Ressaltamos, ainda, que, ao explicitar os diferentes grupos sociais afetados pelo modelo de desenvolvimento, fica marcado o sentido contra-hegemônico da representação de que todos os seres humanos, de forma independente de classe social, raça ou etnia, são afetados pela crise socioambiental.

O modelo de desenvolvimento é representado pelo vocábulo "desenvolvimento". A grafia da palavra separando o prefixo "des" (negação) demarca a característica desse modelo de desenvolvimento que, portanto, não envolve, promove 
segregação, conforme o trecho abaixo, assinalando três características desse modelo: segrega, busca o crescimento ilimitado e se sustenta pela desigual distribuição de danos e prejuízos:

Partilhamos da compreensão de que a reprodução da lógica de desenvolvimento baseado no crescimento ilimitado somente se viabiliza porque distribui de forma desigual danos e violações sobre os povos historicamente discriminados (RBJA, 2014, p. 1).

O sentido contra-hegemônico denotado pela palavra "des-envolvimento" é reiterado no parágrafo final do texto, conforme o trecho a seguir:

Nesse sentido lutamos pelo envolvimento que nos fortalece e nos valoriza enquanto sujeitos de direito, povos da floresta, do campo e da cidade que constroem cotidianamente alternativas a um modelo econômico e político que insiste em nos des-envolver (RBJA, 2014, p. 1).

Nesse excerto, observamos a palavra envolvimento, grifada pelos autores do texto, conferindo-a, portanto, destaque. Também observamos a reiteração do sentido atribuído ao atual modelo de desenvolvimento conforme marcado pelo verbo "desenvolver". Nesse trecho, identificamos outra característica desse modelo evidenciada pelos autores do texto: "a insistência em nos des-envolver". Essa oração denota o sentido de que esse modelo está constantemente criando estratégias para segregar, conforme o sentido do verbo "insistir". Outra questão que ressalvamos refere-se à polarização evidenciada no texto. Por um lado, o atual modelo de desenvolvimento que segrega ("des-envolve") e que vulnerabiliza os povos e grupos sociais por ele afetados. Por outro lado, outros modelos de desenvolvimento ("alternativas a um modelo econômico e político") que envolve os sujeitos políticos ("lutamos pelo envolvimento") e os une na "luta", fortalece e valoriza. Destacamos ainda o sentido de embate, conforme o verbo "lutamos", na busca de modelos alternativos de organização social, evidenciando a luta pela hegemonia do modo de organização social e políticoeconômica.

Os discursos do senso comum são recontextualizados no texto e, por meio da negação, os autores do texto evidenciam a contradição desses discursos, conforme o trecho abaixo:

Ao contrário de um certo "senso comum" ambiental, a poluição não é democrática, não atinge a todos de maneira uniforme e não submete todos os grupos sociais aos mesmos riscos e incertezas. Igualmente é imposta por meio da violência, da desinformação e da desqualificação, da perda dos territórios e do acesso aos bens naturais como condição para expansão do 
modelo, como garantia de lucratividade ao capital. A expansão ilimitada do capital globalizado se faz às custas de injustiças ambientais, mascaradas sob o discurso desenvolvimentista do benefício de todos (RBJA, 2014, p. 1.Grifos nossos).

Os autores do texto enfatizam as contradições do senso comum, as quais ficam demarcadas pelas expressões "Ao contrário" e pela negação "poluição não é democrática, não atinge a todos de maneira uniforme e não submete todos os grupos sociais aos mesmos riscos e incertezas" (grifos nossos). Os textos do senso comum são incorporados para contradizê-los, reafirmando que a distribuição dos riscos e incertezas não atinge a todos de igual forma e que existem grupos sociais que estão submetidos à poluição e aos riscos e incertezas mais que outros.

Nesse parágrafo, a assimetria de poder é evidenciada pelos vocábulos que indicam força: "imposta", "violência" e "perda". Além isso, o uso dos vocábulos "desinformação" e "desqualificação" também evidenciam a assimetria de poder, pois demarcam a fragilidade dos grupos pela ausência de informação e qualificação. Assinalamos a relevância de identificar que as relações sociais são constituídas entre os que têm mais e os que têm menos poder, seja poder como força física (violência física) ou simbólica (informação). Dessa forma, torna-se evidente que nas sociedades contemporâneas não podemos argumentar de forma genérica que todos os seres humanos são afetados pelos prejuízos decorrentes do atual modelo de desenvolvimento, sob o risco de ocultar essas relações de dominação sobre os grupos com menos poder.

Um dos mecanismos de dissimulação das relações de dominação é explicitado ao final desse parágrafo: “A expansão ilimitada do capital globalizado se faz às custas de injustiças ambientais, mascaradas sob o discurso desenvolvimentista do benefício de todos". As injustiças ambientais são representadas como "sendo mascaradas", ou seja, o discurso desenvolvimentista encobre a verdadeira "face" dessas injustiças, dissimulando-as. A estratégia para tal dissimulação é, conforme os autores do texto, "o discurso desenvolvimentista do benefício de todos".

Um dos mecanismos através dos quais a ideologia opera é por meio da unificação, disseminando um discurso de desenvolvimento econômico e social que beneficia a todos indistintamente. Esse discurso não explicita que esse desenvolvimento não contempla a todos de forma igualitária. Ao unificar todos os seres humanos como beneficiados, ofusca que esse modelo submete determinados grupos sociais e 
comunidades a condições insalubres de vida, de moradia e de trabalho e degradação ambiental, agravando a opressão social e as injustiças ambientais.

Ao explicitar esse mecanismo ideológico de dissimulação das injustiças ambientais, fica demarcada a oposição à atual corrente hegemônica da questão ambiental da "modernização ecológica" que conforme Loureiro e Layrargues (2013, p. 64) “compreende ainda que a crise ambiental seja democrática, isso é, a humanidade como um todo, indistintamente, estaria igualmente sujeita aos efeitos nocivos da degradação ambiental planetária, independentemente de qualquer tipo de recorte social".

$\mathrm{O}$ uso da metáfora realça ou encobre aspectos daquilo que representam. $\mathrm{Na}$ análise do texto, observamos duas metáforas: a metáfora da face e a metáfora dos tentáculos, as quais realçam as contradições do atual modelo de desenvolvimento social e político-econômico. No trecho anterior, a metáfora da face, destaca que as injustiças ambientais têm "rostos" que são encobertos, são "mascarados", reforçando a dimensão social da crise, que não afeta apenas elementos naturais; as injustiças ambientais recaem sobre pessoas, conformando relações sociais desiguais. Ainda no texto da Carta, em um parágrafo posterior, os autores reafirmam essa questão: “(...) nós atingidos nos consideramos sujeitos políticos com faces e corpos ameaçados por atores sem rosto, que nos veem como "entraves ao crescimento"” (RBJA, 2014, p. 3).

Para explicitar a relação de dominação sobre essas pessoas, os autores do texto utilizam a mesma metáfora para representar as grandes corporações e, nesse caso, realçam o aspecto de que os agentes sociais dos processos econômicos não são explicitados (“As grandes corporações "sem rosto"”), conforme o trecho a seguir:

As grandes corporações "sem rosto" estendem, sob os auspícios dos Estados Nacionais, seus tentáculos sobre os territórios em busca dos bens naturais que restam e extraem mais-valia da vulnerabilização das comunidades, povos e grupos sociais dotados de menos poder (RBJA, 2014, p. 1).

De acordo com Fairclough (2005), os processos econômicos na nova ordem econômica globalizada são representados sem agentes sociais responsáveis, o que colabora para ofuscar responsabilidades da agência de corporações sobre as questões sociais e ambientais. O texto da Carta Política, também utilizando a metáfora da face, assinala a necessidade de que os agentes econômicos sejam explicitados, assim como o seu papel e sua ação no estabelecimento e manutenção das relações sociais capitalistas 
desiguais e injustas, conforme o trecho a seguir: "Buscamos desmascarar a responsabilidade social corporativa que dificulta e até impede a luta por direitos" (RBJA, 2014, p. 4).

Nesse trecho também assinalamos que as corporações são adjetivadas como "grandes", enfatizando o processo de concentração de capital que ocorre na contemporaneidade, formando megafusões. Harvey (2013) assinala que a centralização financeira é uma das estratégias de proteção dos poderes de monopólio as quais os capitalistas recorrem, buscando domínio por meio do poder financeiro e economias de escalas e posição de mercado. Essas grandes corporações se deslocam e se instalam em locais (países, estados, cidades) que oferecem maiores condições de lucro e rentabilidade (flexibilização de leis trabalhistas e ambientais, subsídios estatais); por consequência, esses processos de deslocalizações corroboram as injustiças ambientais, pois oferecem piores condições de trabalho e de salários, riscos e danos à saúde dos trabalhadores e moradores das regiões onde se instalam. Loureiro (2009, p. 15) afirma que "não é casual que as multinacionais fazem forte movimento em direção à América Latina, à África, à China e à Índia - nestes países e continentes se consegue fazer um processo de expropriação mais intenso do trabalho e garantir maior ganho". Por essa lógica, a localização dos diversos empreendimentos econômicos (indústrias e obras de infraestrutura, por exemplo) não é aleatória, conforme denunciou a RBJA em uma carta pública:

As indústrias mais poluidoras são autorizadas a se instalar nas periferias pobres das cidades, como é o caso da siderúrgica TKCSA, que, com sua "chuva de prata", afeta a saúde das famílias trabalhadoras do bairro de Santa Cruz/RJ. A produção de agrotóxicos - de cujo consumo o Brasil bate seguidos recordes mundiais - pela NUFARM é autorizada a localizar-se em Maracanaú/CE e não nas proximidades dos bairros residenciais de alta renda, reservando às famílias de baixa renda os riscos e danos da acumulação de riqueza para os acionistas do complexo industrial agroquímico (RBJA, 2015).

Utilizando a metáfora dos tentáculos, outra característica desse poder econômico é enfatizada pelos autores do texto: flexibilidade e poder de capilaridade e abrangência nos diversos setores da vida social. Essa representação evidencia a centralização econômica das grandes corporações donde partem os "tentáculos" que, por sua vez, representam flexibilidade e capacidade de atingir diversos setores da sociedade. Por meio dessa metáfora de um animal (e seus tentáculos) os autores do texto realçam a característica dos agentes econômicos que agem para saciar sua "fome" o que 
fica evidenciado ainda nesse mesmo parágrafo, quando relacionam as ações das grandes corporações à "sua ânsia insaciável por lucros crescentes" (grifos nossos).

Tal característica é reforçada nesse parágrafo ao reiterar a metáfora do animal, definindo como predatórias as atividades de expansão das empresas ("seu expansionismo predador") e no parágrafo seguinte, quando os autores do texto atribuem às corporações a capacidade de "capturar" o Estado, como um animal que captura sua presa: "O Estado democrático de direitos, duramente conquistado, uma vez capturado pelas corporações, tornou-se inimigo dos povos atingidos pelos empreendimentos expansionistas" (RBJA, 2014, p. 2) (grifos nossos). Assim, são ratificadas as marcas da força de opressão do modelo social dominante, baseado nas ações de corporações que buscam crescimento e lucro ilimitado e as marcas da fragilidade do grupo oprimido, conforme a oração: "extraem mais-valia da vulnerabilização das comunidades, povos e grupos sociais dotados de menos poder".

Observamos, outrossim, que o texto explicita as relações de dominação entre o Estado e as atividades econômicas ("sob os auspícios do Estado) e entre o Estado e os grupos sociais atingidos pelas atividades econômicas ("tornou-se inimigo dos povos atingidos"). O governo é representado em posição de submissão como patrocinador das atividades econômicas, evidenciando o papel do Estado para atender os interesses privados.

Outro mecanismo de dissimulação da crise socioambiental é explicitado pelos autores da Carta Política: a criação de crises para retroalimentar as corporações e a lucratividade do capital, segundo mostra o trecho a seguir:

\begin{abstract}
Engendram as crises energética e alimentar como se não fossem resultantes de seu expansionismo predador, o mesmo que propõem como solução única e urgente para elas. Para a primeira, mais hidrelétricas, petróleo e gás, agrocombustíveis, parques eólicos e usinas nucleares. Para a segunda, mais agronegócio, monoculturas, erosão da agrobiodiversidade, transgênicos e agrotóxicos. Todas formas de degradação do solo, subsolo, matas e águas, comprometendo o habitat de espécies e o presente e futuro de povos inteiros. Falsas soluções que, na verdade, só resolvem sua ânsia insaciável de lucros crescentes. E agravam a crise socioambiental, à qual se pretende responder com mecanismos de mercantilização da natureza e inclusão social consumista (RBJA, 2014, p. 1-2).
\end{abstract}

As crises energéticas assim como as crises de alimentação são representadas como mecanismos de aumentar os lucros, são criações do próprio sistema para garantir a sua reprodução. $\mathrm{O}$ verbo engendrar denota um sentido de criação imaginativa, são 
crises criadas com um propósito que, nesse caso, conforme o texto, têm como objetivo resolver "sua ânsia insaciável de lucros crescentes". Layrargues (2012) assinala a implicação dessa questão para os embates hegemônicos:

É bom para a hegemonia, portanto, que se pense que o Capital de vez em quando passa por crises - e não que as cria intencionalmente para evoluir -, pois assim ele pode trabalhar de modo despercebido e não suscitar movimentos de contestação por essa irracionalidade (LAYRARGUES, 2012, p. 414. Grifos nossos).

Assim, o texto da Carta Política evidencia outra contradição do atual modelo de desenvolvimento, como a criação oportunizada de crises e suas soluções. É importante caracterizar ainda o caráter manipulador e falseador atribuído a esse mecanismo de gerar crises com o propósito de garantir a manutenção e alimentação do capital, conforme fica marcado pela conjunção "como" e explicitamente pelo adjetivo "falsas". Os autores do texto evidenciam a intrincada relação entre desenvolvimento de tecnologias para sanar essas crises, de acordo com o explicitado no texto: "hidrelétricas, petróleo e gás, agrocombustíveis, parques eólicos e usinas nucleares. Para a segunda, mais agronegócio, monoculturas, erosão da agrobiodiversidade, transgênicos e agrotóxicos" (RBJA, 2014, p.1).

Dessa forma, podemos interrogar em que medida o uso dos transgênicos ou o agronegócio, por exemplo, resolveram a crise dos alimentos ou colaboraram para a concentração de riqueza e poder nas mãos de poucos. A concentração corporativa no setor agroalimentar brasileiro, a título de exemplo, gera grandes impactos socioeconômicos, inclusive para os agricultores e para os trabalhadores do campo. Por trás do faturamento de bilhões da indústria de aves do sul do Brasil, há milhares de agricultores familiares endividados e presos a contratos mal remunerados com frigoríficos (GOMES, 2015).

As "falsas soluções" apontadas pela Carta Política alinham-se à tendência hegemônica no campo da Educação Ambiental do conservadorismo dinâmico.

Essa perspectiva percebe o meio ambiente pela ótica da modernização ecológica, ou seja, destituído de componentes humanos, como uma mera coleção de recursos naturais em processo de esgotamento (...). Deixa à margem das considerações a questão da distribuição desigual dos custos e benefícios da apropriação dos bens ambientais pelos processos desenvolvimentistas e resulta na promoção de reformas setoriais na sociedade sem questionar seus fundamentos de base, inclusive aqueles responsáveis pela própria crise ambiental (LOUREIRO E LAYRARGUES, 2013, p. 66$67)$. 
Reconhecemos que a análise aqui realizada não esgota todos os sentidos produzidos pela Carta Política (e nem poderíamos ter essa pretensão); todavia ressaltamos a relevância de explicitar as contradições e antagonismos do atual modelo hegemônico de desenvolvimento em um momento sócio-histórico de aparentes consensos sobre a questão socioambiental. Concordamos com Loureiro (2009) que:

Hoje, concretamente, fazer uma história que supere o atual cenário de degradação e barbárie implica atuar no enfrentamento das formas de expropriação, dominação e opressão que conformam as relações sociais capitalistas, por meio de projeto político que envolve e tem nos agentes sociais expropriados sua base de sustentação (LOUREIRO, 2009, p. 17).

\section{A EDUCAÇÃO EM CIÊNCIAS E A CRISE SOCIOAMBIENTAL: FORTALECENDO SENTIDOS EMANCIPATÓRIOS}

Os sentidos emancipatórios, conforme o título do presente trabalho, evidenciam o comprometimento "com uma visão de mundo transformadora inconformada com um mundo injusto e insustentável em que vivemos" (GADOTTI, 2012, p. 2). Ao desvelar discursos que sustentam ou ocultam as injustiças ambientais, acreditamos que podemos colaborar para contrapor interpretações hegemônicas sobre a problemática socioambiental e as injustiças ambientais que dela decorrem. No presente texto, assinalamos dois sentidos contra-hegemônicos que acreditamos poder fortalecer no campo da Educação em Ciências a partir das análises realizadas: os discursos sobre as relações entre seres humanos e natureza e os discursos sobre o atual modelo de desenvolvimento social e político-econômico.

Em conformidade ao que apontamos na análise da Carta Política, as relações entre os seres humanos e destes com o ambiente não prescindem de relações assimétricas de poder, em que resultam em explorações, sofrimento e opressão para muitos grupos sociais. Desse modo, assinalamos a relevância de que não podemos sustentar os discursos do senso comum que encobrem a distribuição desigual dos prejuízos e riscos ambientais. Antes, é fundamental explicitar o modo como diferentes grupos sociais agem e interagem com o ambiente, problematizando questões como, por exemplo, a poluição, para além dos aspectos físico-químicos e biológicos.

A discussão, portanto, deve ser ampliada para contemplar os aspectos socioculturais e político-econômicos relativos aos modos como são estabelecidas relações de dominação entre os interesses dos agentes econômicos, como as grandes 
corporações e os seus diversos empreendimentos e os direitos das comunidades que são colocadas em situação de vulnerabilidade social e ambiental, sendo expropriadas de seus saberes, seus territórios, suas culturas.

Dessa forma, os autores da Carta Política ao identificarem cada um dos grupos que assinam o documento enfatizam a necessidade de que devemos considerar não só os seres humanos trabalhadores do campo, os seres humanos quilombolas ou os seres humanos indígenas, por exemplo, que sofrem com a expropriação de suas terras, de seus saberes originais, de seus vínculos com o ambiente, mas também devemos considerar os seres humanos que concentram riquezas e poder para decidir inclusive os destinos de uma comunidade ribeirinha ou de famílias de pequenos agricultores, em nome do desenvolvimento ou crescimento econômico. Portanto, a Educação em Ciências ao ter como um dos objetivos prioritários do ensino de Ciências Naturais a reconstrução das relações entre seres humanos e natureza (VENTURA e FREIRE, 2017), não pode continuar a sustentar os discursos que representam essas relações de forma genérica, como se todos os seres humanos interagissem com os outros e com o ambiente da mesma forma, com os mesmos interesses e sob os mesmos riscos e incertezas. Tais relações devem ser compreendidas a partir dessa assimetria de poder, que resulta, para muitos, em opressão, vulnerabilidade e injustiças e, para outros poucos, riqueza e poder.

Com relação aos discursos sobre o desenvolvimento político-econômico, assinalamos a importância de que seja dada visibilidade aos diferentes atores sociais e aos processos político-econômicos, distinguindo as responsabilidades e os interesses corporativos, assim como os interesses e responsabilidades do Estado e, conforme a Carta política, "desmascarar a responsabilidade social corporativa”.

Temas como crise energética, agrocombustíveis e transgênicos, por exemplo, estão presentes no campo da Educação em Ciências e devem articular questões referentes ao desenvolvimento científico e tecnológico e o seu comprometimento com a lucratividade do capital, politizando essas questões para além da compreensão das etapas físico-químicas dos processos produtivos. Conforme observamos na análise da Carta Política, um dos principais aspectos ressalvados pela metáfora da face refere-se ao ocultamento dos diferentes sujeitos e atores dos processos sociais e políticoeconômicos. 
Ao enfatizar as contradições do atual modelo de desenvolvimento, o texto amplia o debate, relevando a sua dimensão política, de modo que devemos problematizar o discurso do desenvolvimento: para quem, por que, para quê?

No presente texto, estabelecemos aproximações entre os campos da Educação em Ciências e a Justiça Ambiental, por meio da análise de um evento social concreto do Movimento Brasileiro por Justiça Ambiental (Rede Brasileira de Justiça Ambiental). Martinez-Alier et al. (2014) ressaltaram a riqueza da integração entre as organizações por justiça ambiental e as redes que elas formam na adoção de conceitos do campo da ecologia política, tais quais: justiça ambiental, racismo ambiental, biopirataria, entre outros.

Com a análise da Carta Política, ao explicitar os discursos hegemônicos, entendemos que podemos colaborar para a elaboração de representações discursivas contra-hegemônicas no campo da Educação em Ciências. Entretanto, sabemos também que os processos de recontextualização dos discursos no novo contexto não ocorrem sem lutas hegemônicas no campo. Assim, observamos que não se trata simplesmente de colonizar as práticas da Educação em Ciências com esses novos sentidos; é preciso considerar o potencial de luta sobre formas de apropriação entre os grupos sociais na definição, por exemplo, acerca do que dever ser ensinado nas aulas e sobre os objetivos da Educação em Ciências. Esperamos, contudo, ter contribuído com o fortalecimento de recursos simbólicos e materiais nessa rede de práticas os quais possam sustentar possibilidades de ação social transformadora, questionando os sentidos produzidos pelo senso comum sobre a crise socioambiental e as injustiças ambientais que dela decorrem.

\section{REFERÊNCIAS}

ACSELRAD, H. Ambientalização das lutas sociais: o caso do movimento por justiça ambiental. Estudos avançados, v. 24, n. 68, p. 103-119, 2010.

BAZZUL, J. Neoliberal ideology, global capitalism and science education: engaging the question of subjectivity. Cultural Studies of Science Education. v. 7. p. $1001-1020$, 2012.

BENCZE, J. L. 'Spending' Cultural Capital on People and the Planet: Theory \& Practice. National Value of Science Education, 2007. Disponível em: http://kdf.mff.cuni.cz/ kekule/odkazy/Bencze.pdf. Acesso em: 16 de novembro de 2013. 
BENCZE, J. L.; CARTER, L. Globalizing students acting for the common good. Journal of Research in Science Teaching, v. 48, n. 6, p. 648-669, 2011.

BENCZE, J., CARTER, L., KRSTOVIC, M. Science \& Technology Education for Personal, Social \& Environmental Wellbeing: Challenging Capitalists' Consumerist Strategies. Revista Brasileira de Pesquisa em Educação em Ciências, v. 14, nov. 2014.

BRASIL. MINISTÉRIO DO MEIO AMBIENTE. Manifesto de Lançamento da Rede Brasileira de Justiça Ambiental. Disponível em: http://www.mma.gov.br/informma/item/8077. Acesso em: 28 de novembro de 2017.

CHIAPELLO, E. FAIRCLOUGH, N. Understanding the new management ideology. A transdisciplinary contribution from critical discourse analysis and the new sociology of capitalism. Discourse \& Society. v. 13, no 2, p. 185 - 208, 2002.

CHOULIARAKI, L.; FAIRCLOUGH, N. Discourse in Late Modernity: Rethinking Critical Discourse Analysis. Edinburgh: Edinburgh University Press, 2007.

COSENZA, A.; FREIRE, L.; ESPINET; M; MARTINS, I. Relações entre justiça ambiental, ensino de ciências e cidadania em construções discursivas docentes. Revista Brasileira de Pesquisa em Educação em Ciências. v. 14, nº 2, 2014.

FAIRCLOUGH, N. Análise Crítica do Discurso como método em pesquisa social científica. In: Wodak e Meyer. Methods of critical discourse analysis (org.) 2 ed. Londres: Sage, 2005. Tradução: Iran Ferreira de Melo. Disponível em: http://www.revistas.usp.br/linhadagua/article/view/47728. Acesso em: 10 de novembro de 2017.

. Analysing discourse: Textual analysis for social research. Routledge. 2003.

. Discurso e mudança social. Editora UnB. Brasília, 2001.

2000 .

Language and neo-liberalism. Discourse \& Society, v. 11, n. 2, p. 147-148,

Semiose, mediação e ideologia: uma visão dialética. Revista Parágrafo. v. 4, n. 1, p. 17-27, 2016. Disponível em: http://revistaseletronicas.fiamfaam.br/index.php/recicofi/article/view/375 Acesso em: 08 de julho de 2017.

GADOTTI, M. Trabalho e educação numa perspectiva emancipatória. II FÓRUM MUNDIAL DE EDUCAÇÃO PROFISSIONAL E TECNOLÓGICA. Democratização, emancipação e sustentabilidade. Florianópolis, 28 de maio a 1 de junho de 2012. Disponível em: http://www.seduc.mt.gov.br/educadores/Documents/. Acesso em: 09 de novembro de 2017. 
GOMES, M. Globalização e concentração no sistema agroalimentar brasileiro. Monitor, $\mathrm{n}^{\mathrm{o}}$ 1, dezembro, 2015. Disponível em: http://reporterbrasil.org.br/wp-

content/uploads/2016/07/Monitor1 PT.pdf. Acesso em: 10 de novembro de 2017.

HARVEY, D. O novo imperialismo. $7^{\text {a }}$ Ed. São Paulo: Edições Loyola, 2013.

LAYRARGUES, P. P. A crise ambiental e suas implicações na educação. In: Quintas, J.S. Pensando e praticando a educação ambiental na gestão do meio ambiente. Brasília: Edições Ibama, 2002.

Para onde vai a Educação Ambiental? O Cenário Político- Ideológico da Educação Ambiental Brasileira e os Desafios de uma Agenda Política. Revista Contemporânea de Educação, v. 7, n. 14, 2012.

LOUREIRO, C. F. B. Mundialização do capital, sustentabilidade democrática e políticas públicas: problematizando os caminhos da Educação Ambiental. Revista Ambiente \& Educação, v.14, p. 11-22, 2009.

LOUREIRO, C. F. B.; LAYRARGUES, P. P. Ecologia política, justiça e educação ambiental crítica: perspectivas de aliança contra-hegemônica. Trab. educ. saúde v.11, n. 1, p. 53-71, 2013.

MARTINEZ-ALIER J., et al. Between activism and science: grassroots concepts for sustainability coined by Environmental Justice Organizations. Journal of Political Ecology, v. 21, p. 19-60, 2014.

MARTINS, I.; et al. Contribuições da análise crítica do discurso para uma reflexão sobre questões do campo da Educação Ambiental: olhares de educadores em ciências. Pesquisa em Educação Ambiental, v. 3, n. 1, p. 129-154, 2008.

PACHECO, T. Boletim Combate Racismo Ambiental. [blog na internet]. Desigualdade, injustiça ambiental e racismo: uma luta que transcede a cor. Disponível em:

http://racismoambiental.net.br/?page_id=169061. Acesso em: 09 de novembro de 2017. Artigo original: PACHECO, T. Inequality, environmental injustice, and racism in Brazil: beyond the question of colour. Development in Practice, Volume 18, Number 6, November 2008.

REDE BRASILEIRA DE JUSTIÇA AMBIENTAL (RBJA). Carta Política do VI Encontro Nacional da Rede Brasileira de Justiça Ambiental. Disponível em: https://redejusticaambiental.wordpress.com/2014/09/05/carta-politica-do-vi-encontronacional-da-rede-brasileira-de-justica-ambiental/. Acesso em: 10 de julho de 2017.

REDE BRASILEIRA DE JUSTIÇA AMBIENTAL (RBJA). Carta Pública da Rede Brasileira de Justiça Ambiental - Dia Mundial do Meio Ambiente. 2015. Disponível em: https://redejusticaambiental.wordpress.com/2015/06/05/carta-publica-da-redebrasileira-de-justica-ambiental-dia-mundial-do-meio-ambiente-05-de-junho-de-2015/. Acesso em: 10 de julho de 2017. 
REDE BRASILEIRA DE JUSTIÇA AMBIENTAL (RBJA). Nota Pública da RBJA Dia da consciência negra. Disponível em: https://redejusticaambiental.wordpress.com/2015/11/21/nota-publica-da-rbja-dia-daconsciencia-negra/. Acesso em: 22 de abril de 2016.

RESENDE, V. M.; RAMALHO, V. Análise de discurso crítica. São Paulo: Contexto, 2006.

Análise de discurso crítica, do modelo tridimensional à articulação entre práticas: implicações teórico-metodológicas. Linguagem em (Dis) curso - LemD, v. 5, n.1, p. 185-207, 2004.

SANTOS, C. F.; GONÇALVES, L. D.; DA SILVA MACHADO, C. R. Educação ambiental para justiça ambiental: dando mais uns passos. REMEA Revista Eletrônica do Mestrado em Educação Ambiental, v. 32, n. 1, p. 189-208, 2015.

SAUVÉ, L. Educación Científica y Educación Ambiental: Un cruce Fecundo. Revista Enseñanza de las Ciencias, v. 28, n.1, p.5 -18, 2010.

THOMPSON, J. B. Ideologia e cultura moderna: teoria social crítica na era dos meios de comunicação de massa. 9. ed. Petrópolis: Vozes, 2011.

TREIN, E. A contribuição do pensamento marxista à educação ambiental. In: LOUREIRO, C.F.B. A questão ambiental no pensamento crítico: natureza, trabalho e educação. Rio de Janeiro: Quartet, 2007.

VASCONCELOS, E. R.; FREITAS, N.M.S.; FERREIRA, D. T.; VALENTE, J.A.S. Educar para a justiça social e ambiental: que questões pensar no contexto do ensino e da formação de professores de ciências? Revista Brasileira de Pesquisa em Educação em Ciências, v. 14, n. 2, p. 245-254, 2014.

VASCONCELLOS, M. M. N.; LOUREIRO, C.F.B.; QUEIROZ, G.R.P.C. A Educação Ambiental e a Educação em Ciências: Uma Colaboração no Enfrentamento da Crise Socioambiental. Revista Brasileira de Pesquisa em Educação em Ciências. V. 10, n. 1, p. 01-19, 2010.

VENTURA, G., FREIRE, L. A Análise Crítica do Discurso como caminho teóricometodológico na compreensão e no enfrentamento da questão ambiental. In: VIII ENCONTRO DE PESQUISA EM EDUCAÇÃO AMBIENTAL. 2015. Rio de Janeiro, Anais do VIII EPEA. Disponível em: http://epea.tmp.br/epea2015 anais/search/. Acessado em: 22 de fevereiro de 2016.

Análise discursiva sobre as finalidades da Educação em Ciências no Currículo Mínimo de Ciências/Biologia da rede estadual de ensino do Rio de Janeiro. Alexandria: Revista de Educação em Ciência e Tecnologia. v. 10, n. 1, p. 305-327, 2017.

WALS, A.; BRODY, M., DILLON, J.; STEVENSON, R. Convergence Between Science and Environmental Education. Science Education, 344, p. 583-584, 2014. 